\title{
COMPORTAMENTO E CONTROLE DA Diatraea saccharalis NA CULTURA DA CANA-DE-AÇÚCAR
}

\author{
SANDOVAL, Sérgio Santos ${ }^{1}$ \\ SENÔ, Kenji Cláudio Augusto ${ }^{2}$
}

Recebido em: 2009. 10.02

Aprovado em: 2010.02 .10

ISSUE DOI: $10.3738 / 1982.2278-311$

RESUMO: A cana-de-açúcar originária do Sudeste Asiático vem sendo cultivada desde épocas remotas. A exploração canavieira assentou-se, inicialmente, sobre a espécie Saccharum. officiarum. Novas variedades foram obtidas pelo cruzamento da S. officiarum com espécies do gênero Saccharum e através de recruzamentos com as espécies ascendentes. A substituição dos derivados do petróleo por biocombustíveis estimulou a demanda global de etanol, pois além de constituir uma fonte de energia renovável, polui bem menos que os combustíveis fósseis, não agredindo o meio ambiente. O Brasil tornou-se desta forma, o maior produtor mundial de cana-de-açúcar, quer pela área cultivada, quanto pelo volume da produção. As grandes extensões cultivadas pela cana-de-açúcar poderão causar danos econômicos, pois uma única doença ou praga pode provocar a perda de toda a cadeia produtiva. O presente trabalho objetivou o estudo do comportamento e controle da Diatraea saccharalis na cultura da cana-de-açúcar, uma vez que a broca da cana é a mais importante praga no Estado de São Paulo para essa cultura, ocorrendo durante todo o desenvolvimento da cultura, tornando-se desta forma necessários o monitoramento e o controle da praga, com a finalidade de evitar danos na qualidade e quantidade da cana-deaçúcar.

Palavras-chave: Cana-de-açúcar, Diatraea saccharalis, Monitoramento, Controle biológico.

SUMMARY: The original sugarcane of the Asian Southeast has been cultivated from remote times. The sugar cane exploration settled, initially, about the species $S$. officiarum. New varieties were obtained by the crossing of S. officiarum with species of the gender Saccharum and through retry-cruzaments with the ascending species. The substitution of those derived of the petroleum for biocombustíveis stimulated the global demand of etanol, because besides constituting a renewable source of energy, it pollutes much less than the fossil fuels, not attacking the environment. Brazil became this way, the largest world producer of sugarcane, wants for the cultivated area, as for the volume of the production. The great extensions cultivated by the sugarcane, they can cause economical damages, because a single disease or curse, it can provoke the loss of the whole productive chain. The present work aimed at the study of the behavior and control of the Diatraea saccharalis in the culture of the sugarcane, once the drill of the cane is the most important curse in the state of São Paulo, happening during the whole development of the culture, becoming this necessary way the monitoramento and the control of the curse, with the purpose of avoiding damages in the quality and amount of the sugarcane.

Keywords: Sugarcane, Diatraea saccharalis, Monitoring, Biological control.

\section{INTRODUÇÃO}

A cana-de-açúcar é uma gramínea de clima tropical e tem sido cultivada em regiões de clima quente com solos férteis e bem drenados, com características climáticas compatíveis com as exigências técnicas da cultura. (CESNIK; MIOCQUE, 2004).

\footnotetext{
${ }^{1}$ Engenheiro agrônomo e Pós-graduando em Agroindústria Canavieira na Faculdade Dr. Francisco Maeda/FE.

${ }^{2}$ Doutor em Agronomia (Entomologia Agrícola) pela Universidade Estadual Paulista Júlio de Mesquita Filho e professor da FAFRAM/FE - Ituverava.
} 
Seu uso principal é como matéria-prima a ser fornecida, por esmagamento dos seus colmos para a extração de seu caldo, a um complexo industrial, com a finalidade de produzir açúcar, álcool, fermento e inúmeros outros derivados quer para fins alimentícios como para a indústria química.

A necessidade dos países desenvolvidos substituírem os derivados de petróleo por biocombustíveis estimulou a demanda global de etanol. Em vários países, sobretudo nos Estados Unidos, a produção local não vem sendo suficiente para o consumo. O setor sucroalcooleiro do Brasil rapidamente respondeu a essa demanda com safra recordes consecutivas de cana-de-açúcar (AGRIANUAL, 2009).

Segundo Fuser (2008), os biocombustíveis apresentam duas vantagens decisivas em relação ao petróleo, pois oferecem uma fonte de energia renovável, fornecida pelos vegetais (biomassa) frente aos combustíveis fósseis e constituem um recurso energético que polui bem menos que o petróleo ou o carvão, sendo que o seu consumo não agride o meio ambiente.

O Brasil é o maior produtor mundial de cana-de-açúcar. Pouco mais de um terço da área cultivada com cana no mundo está em solo brasileiro. Essa liderança conta com uma vantagem significativa, pois pelos cenários próximo-futuros, ainda há espaço para expansão da atividade sucroalcooleira no Brasil, uma vez que a área cultivada, na safra 2006/07, ocupou cerca de 6,2 milhões de hectares, significando quase $0,5 \%$ da atual área utilizada em agricultura e pecuária (CANAOESTE, 2009).

Afirma Carvalho (2009), que pelos cálculos da Embrapa, o Brasil tem 90 milhões de hectares que podem ser utilizados para a produção agrícola sem que, para isso, se derrube uma árvore sequer. Essa área é praticamente o dobro da utilizada atualmente. O Brasil também dispõe de 300 milhões de hectares de pastagens para a criação extensiva de gado, onde qualquer ganho de produtividade representará milhões de hectares extras para a agricultura.

Conforme a Unica (2009), a safra de cana-de-açúcar do centro-sul brasileiro deverá crescer 16\% em 2008/09, para 498,1 milhões de toneladas. Para a nova safra brasileira, a produção de açúcar deverá aumentar para 28,6 milhões de toneladas, ante 26,2 milhões de toneladas na safra anterior.

Entretanto Fuser (2008) alerta, que a monocultura traz desvantagens ambientais, sociais e econômicas. No setor econômico, por apresentar enormes riscos, já que uma única doença ou praga, ou a queda do produto no mercado podem colocar a perder toda a cadeia produtiva regional.

Desde que começou a cultivar as plantas para fins alimentícios, medicinais e outros, o homem passou a ter problemas com animais e delas se alimentavam, competindo pelo 
mesmo alimento e frequentemente causando prejuízos, surgindo daí o conceito de praga. Hoje, com a introdução da filosofia do manejo integrado de pragas na agricultura moderna, consideram-se os fatores ambientais e econômicos para definir tal conceito. Dessa forma, as pragas são os organismos que, a partir de certo nível populacional, causam prejuízos ao homem (PINTO, 2006).

Conforme Gallo et al. (2002), os danos causados pelos insetos às plantas são variáveis, podendo ser observados em todos os órgãos vegetais. Dependendo da espécie e da densidade populacional da praga, do estádio de desenvolvimento e estrutura vegetal atacada e da duração do ataque, poderá haver maior ou menor prejuízo quantitativo e qualitativo. Tais danos são variáveis de um país para outro, de acordo com características, variedades, técnicas agronômicas utilizadas e, obviamente, características socioeconômicas.

Pelo exposto, torna-se necessário o estudo das doenças ou pragas que podem afetar as plantações de cana-de-açúcar, com a finalidade de assegurar boa produtividade da matériaprima, responsável pela produção do açúcar e do álcool, dos quais o Brasil é o maior produtor mundial.

O presente trabalho teve por objetivo, estudar o comportamento e controle da Diatraea saccharalis (FABRICIUS, 1794) (Lepidoptera: Crambidae) na cultura da cana-de-açúcar.

\section{REVISÃO DA LITERATURA}

\section{A CULTURA DA CANA-DE-AÇÚCAR}

A cana-de-açúcar originária do sudeste da Ásia é cultivada desde épocas remotas, sendo que a exploração canavieira assentou-se, no início, sobre a espécie S. officinarum. O surgimento de várias doenças e de uma tecnologia mais avançada exigiu a criação de novas variedades, as quais foram obtidas pelo cruzamento da S. officinarum com as outras quatro espécies do gênero Saccharum e, posteriormente, através de recruzamentos com as ascendentes. Os trabalhos de melhoramento persistem até os dias atuais e conferem a todas as variedades em cultivo uma mistura das cinco espécies originais e a existência de cultivares ou variedades híbridas. A importância da cana-de-açúcar pode ser atribuída à sua múltipla utilização, podendo ser empregada in natura, sob a forma de forragem, para alimentação animal, ou como matéria-prima para a fabricação de vários produtos (AGROB YTE, 2009).

\section{ASPECTOS FITOSSANITÁRIOS}

De acordo com Landell et al. (2003a), o início das pesquisas fitossanitárias com a 
cana-de-açúcar está associada ao surgimento da Gomose no séc. XIX, o Mosaico em 1922, o Carvão em 1947 e a expansão para áreas de cerrado em 1975, com o advento do Programa Nacional do Álcool - PROÁlCOOL, criado pelo governo federal (Decreto 76593 de 14/11/1975). A partir da criação do PROÁLCOOL um novo ciclo de pesquisa se iniciou dando suporte a expansão da cultura no país. Em poucos anos, a área plantada com a cana-deaçúcar triplicou, invadindo áreas consideradas menos aptas principalmente nas regiões de cerrados. Para enfrentar os novos desafios advindos dessa expansão iniciaram-se os programas de melhoramento genético visando à obtenção de novas variedades, que surgiram no Brasil no começo do século passado.

Landell et al. (2003b) cita três programas de melhoramento genético no Brasil:

a) O programa de melhoramento do Instituto Agronômico de Campinas - IAC;

b) O programa de melhoramento da Cooperativa dos Produtores de Açúcar e Álcool do Estado de São Paulo - COPERSUCAR;

c) O programa de melhoramento das Universidades Federais que compõem a Rede

Interuniversitária para o desenvolvimento do Setor Sucroalcoleiro - RIDESA.

Atualmente, o Centro de Tecnologia Canavieira (CTC) mantém diversos programas de pesquisas em andamento. De seus estudos surgiram, por exemplo, as variedades nacionais de cana-de-açúcar dotadas dos melhores índices de produtividade, brotação de soqueira, teor de sacarose e resistência a doenças e pragas. Atua decisivamente para manter o Brasil na vanguarda mundial da produção de açúcar e etanol. As linhas de pesquisas mantidas pelo CTC abrangem as diferentes etapas dos processos produtivos e industriais destes setores. Essa ampla atuação garante que os esforços no desenvolvimento de novas tecnologias para o mercado se convertam em benefícios para todo o setor, desde o planejamento do plantio até a entrega do produto final. O CTC atua no desenvolvimento de pesquisas para toda a cadeia produtiva da cana-de-açúcar, do campo à agroindústria. Essa ampla atuação garante o desenvolvimento equilibrado do setor e permite acumular ganhos de eficiência nas diversas etapas do processo (CTC, 2009).

A duração de uma variedade é limitada e, por esta razão, os trabalhos de criação de novas variedades têm sido contínuos e permanentes a fim de se obter novos genótipos capazes de fazer frente às adversidades do ambiente. Seja por degenerescência ou por necessidade de aumento de produção a busca de novas variedades, conduz a uma verdadeira evolução no cultivo da cana-de-açúcar, tornando-se um dos principais pilares da pesquisa no setor canavieiro para alcançar tal objetivo. O Estado de São Paulo é um dos melhores exemplos de ganho de produtividade. 
A degenerescência de uma variedade pode ser atribuída a vários fatores. King; Mungomery; Hugues (1965) apontaram que as principais causas são: a queda de fertilidade do solo e o efeito cumulativo de danos provocados por doenças e pragas. Como se observa, são todos fatores inerentes ao ambiente de cultivo, pois a variedade por si só é incapaz de sofrer alterações.

No que se refere às doenças provocadas por fungos, bactérias, vírus e micoplasma, Sanguino (1998), relatou que no Brasil foram diagnosticadas 40, entre as 177 relacionadas em cultivo de cana-de-açúcar no mundo. Historicamente, no mundo são consideradas 4 as doenças mais importantes para a cultura da cana-de-açúcar, sendo elas: Carvão, Raquitismo das soqueiras, Escaldaduras das folhas e o Mosaico, todas basicamente controladas através do melhoramento genético de variedades (SANTOS, 2003). Por outro lado, às pragas (insetos, nematóides e ervas daninha) são os principais fatores limitantes da produção da cana-deaçúcar e para estes, faz-se necessário lançar mão do uso de produtos tóxicos ao homem e outros organismos vivos não alvo, resultando, desta forma, em problemas ambientais e elevando o custo da produção. De acordo com Luchini (1999), os agroquímicos são classificados como micropoluentes para os ecossistemas e o impacto provocado por eles, em solos, suprimentos aquíferos e alimentícios, tem sido objeto de constantes estudos e discussões.

O uso dos inseticidas organoclorados em um passado recente, em especial, os clorados (DDT, BHC, Aldrin e etc...), que possuem alto poder residual, conferiam proteção às lavouras, evitando o ataque dos insetos praga, mas por outro lado, passavam progressivamente do solo para os cereais comestíveis, para as ervas e eventualmente para os animais domésticos. Diante dessa realidade, na década de 80, foi necessária a proibição desses produtos, visando reduzir a poluição ambiental e a contaminação dos alimentos, além da diminuição dos problemas com a resistência das pragas, desenvolvida como resposta às prolongadas exposições a esses inseticidas. Em decorrência dessa proibição, visando uma agricultura mais coerente com os princípios ecológicos e de saúde pública surgiu a necessidade de se realizar novas pesquisas em busca de outros produtos que causam menor impacto ambiental, tais como: reguladores de crescimento dos insetos, feromônios, repelentes ou atraentes e bioinseticidas, que atuam com especificidade, sem afetar o meio ambiente e os organismos que nele vivem (NAKANO et al., 2001).

A utilização de agentes de controle na cultura da cana-de-açúcar, principalmente, contra pragas de solo, deveria compor uma estratégia de manejo integrado, onde fariam parte de um conjunto de práticas aplicáveis tais como: o controle biológico, a rotação de cultura e o 
constante monitoramento de pragas (Manejo Integrado de Pragas - MIP). Na maioria dos casos, os agrotóxicos são utilizados como o único método de controle, o que tem acarretado uma série de impactos negativos ao ambiente (MACHADO; HABIB, 2009).

A partir do momento em que a agricultura passou da fase de subsistência para uma atividade mais comercial, provavelmente o homem tenha tomado consciência dos prejuízos provocados pelas pragas. Uma agricultura intensiva (monocultura), como ocorre com o cultivo da cana-de-açúcar, provoca mudanças no meio ambiente, alterando as características do meio físico, reduzindo a biodiversidade, e refletindo de formas diferentes sobre a biota local, sendo prejudicial a algumas espécies e não a outras (MACHADO, HABIB, 2009).

De qualquer forma, considerando as interrelações entre as espécies que habitam o agroecossistema, este impacto na biodiversidade leva sempre a desequilíbrios ecológicos, o que favorece ao desenvolvimento de pragas e doenças. De acordo com Colborn et al. (1997), os resíduos de substâncias químicas sintéticas, principalmente agrotóxicas, na alimentação, têm afetado a saúde de todos os consumidores, diminuindo a fertilidade em homens e aumentando as doenças de câncer e anomalias dos órgãos reprodutivos da espécie humana e animais.

Por outro lado, há também de ser ressaltado o grande avanço que se teve, no setor canavieiro, com pesquisas inerentes ao controle biológico. Cita-se como exemplo o controle da broca da cana-de-açúcar, Diatraea saccharalis (FABRICIUS, 1794) (Lepidoptera: Crambidae), das cigarrinhas das folhas Mahanarva posticata (Stäl., 1854) (Hemiptera: Cercopidae) e das cigarrinhas das raízes Mahanarva fimbriolata (Stäl., 1855) (Hemiptera: Cercopidae) e da broca dos rizomas Migdolus fryanus (Westwood, 1863) (Coleoptera: Cerambycidae).

\section{A BROCA DA CANA-DE-AÇÚCAR (Diatraea saccharalis)}

Para Nakano et al (2002), a broca-da-cana é a mais importante praga no Estado de São Paulo, cujo adulto é uma mariposa de hábitos noturnos, realizando a postura na parte dorsal das folhas.

Conforme Macedo; Botelho (1988), a cana-de-açúcar é um agroecossistema que abriga numerosas espécies de insetos, sendo que algumas delas, dependendo da época do ano e da região, podem ocasionar sérios prejuízos econômicos. Muitas outras espécies, porém, são benéficas e podem exercer papel importante no controle das espécies-pragas, como $D$. saccharalis, tida como a mais importante praga dessa cultura, por sua ampla distribuição e 
dimensão dos prejuízos que causa.

Conforme Pinto (2006), a broca-da-cana ocorre durante todo o desenvolvimento da cultura, entretanto, sua incidência é menor quando a planta é jovem e não possui entrenós formados. A cana de ano e meio, que é plantada no começo do ano, no Estado de São Paulo, geralmente é mais atacada pela broca no verão, e na cana de ano, plantada em setembrooutubro, o ataque é mais intenso no inverno. Nos outros estados e em certas variedades, o ataque da broca é quase constante o ano todo, com um pequeno declínio no inverno.

Observam Nakano et al. (2002), que após 4 a 9 dias da postura, as larvas recémeclodidas, passam a se alimentar do parênquima das folhas. As lagartinhas descem pela folha penetrando no colmo, perfurando-o na região dorsal. No interior do colmo cavam galerias permanecendo até o estágio adulto. Após cerca de 40 dias, as lagartas com 2,2 a 2,5 cm, abrem um orifício, fechando-o com fios de seda e serragem. Nessa fase, transforma-se em mariposas, saindo pelo orifício aberto e atingem novas plantas.

Conforme Pinto (2006), o monitoramento da população da praga, realizado por meio de levantamentos da quantidade de lagartas, serve para definir o momento certo para a adoção de uma medida de controle. Esse monitoramento é efetuado durante a fase vegetativa da cultura, até sua maturação. A estimativa de danos é realizada no momento da colheita, na frente de corte, ou na chegada da cana na usina, servindo para identificar as áreas-problema que deverão ser monitoradas na safra seguinte.

O ciclo completo do inseto varia de 53 a 60 dias, dependendo das condições climáticas. Esses insetos podem ter ao longo do ano de 4 a 5 gerações (NAKANO et. al., 2002).

Para os autores os prejuízos decorrentes do ataque são a perda de peso devido ao mau desenvolvimento das plantas atacadas, secamento dos ponteiros, enraizamento aéreo, brotação lateral, morte de algumas plantas atacadas, quebra do colmo na região da galeria e redução da quantidade de caldo. Além desses, o principal prejuízo é causado pela ação de agentes patológicos, como o Fusarium moniliforme e Colletotrichum falcatum, que penetram pelo orifício ou são arrastados juntamente com a lagartinha, ocasionando, respectivamente, a podridão-de-fusarium e a podridão-vermelha, responsáveis pela inversão e perda de sacarose no colmo.

Quanto aos danos, Guagliumi (1972/73) e Gallo et al.(1988) afirmaram que as lagartas se alimentam nos primeiros dias dos tecidos foliares, penetrando, em seguida, no interior dos colmos. Seus prejuízos diretos originam-se das galerias que fazem nos colmos, provocando perda de peso e tombamento da planta pelo vento, entre outros. Indiretamente, favorecem a 
penetração de fungos nas plantas, causando a podridão vermelha do colmo, levando à inversão da sacarose e diminuição da produção de álcool.

Outras pragas importantes que atacam a cultura da cana-de-açúcar, citadas por Nakano et al. (2002), são a broca-gigante (Castnia licus), mais comum no nordeste brasileiro, algumas lagartas desfolhadoras (curuquerê-dos-capinzais (Mocis latipes), lagarta-do-cartucho do milho (Spodoptera frugiperda) e lagarta-do-trigo (Pseudaletia sequax) e ainda os pulgões, cochonilhas, cigarrinhas e lagarta-elasmo (Elasmopalpus lignosellus).

Afirma Machado (1988), que a produção de alimentos teve grande aumento devido ao uso de defensivos químicos para controlar insetos pragas. Isso, tempos atrás, foi uma revolução na agricultura. Porém, se esses defensivos forem usados sem critério e continuamente, poderão causar sérios problemas ambientais, tais como a presença de resíduos em alimentos e desequilíbrio ecológico. Pensando nos problemas ambientais, entomologistas se preocuparam em utilizar outras formas de controle, avançando em pesquisas com inimigos naturais e assim conseguindo utilizá-los, sendo esse método chamado controle biológico de pragas.

O controle biológico é utilizado na agricultura para substituir substâncias químicas (inseticidas e pesticidas) (ODUM, 1988).

Conforme Braga et al. (2003) e Bug Agentes Biológicos (2009), o controle biológico tem como finalidade manter as espécies de pragas em níveis aceitáveis através da introdução de um predador natural, parasitóide ou microrganismo que lhe cause doença ou morte, pois todas as espécies de plantas e animais possuem inimigos naturais que atacam seus vários estágios de vida.

Para Belotti (1992), esse controle pode ser visto sob dois aspectos o controle biológico natural ou clássico, que ocorre sem o auxílio do homem, ou seja, os inimigos naturais não são criados em laboratório e nem liberados ao campo e o controle biológico aplicado que envolve a intervenção humana, onde a produção dos inimigos naturais é realizada em laboratório para posterior liberação à cultura.

Da mesma forma Alves; Lopes (2008), afirmam que o controle biológico é utilizado para o controle das cigarrinhas da cana-de-açúcar há muito tempo para a cigarrinha-das-folhas no nordeste do país, e hoje, em cerca de um milhão de hectares, aplica-se Metarhizium anisopliae, o fungo-verde, utilizado para o controle da cigarrinha-das-raízes, problema recente para a cana-de-açúcar na região sudeste.

Para Altieri. Silva; Nicholls (2003), a biodiversidade é crucial para o estabelecimento efetivo do controle biológico. 
O controle biológico da broca iniciou-se com as moscas, mas depois se optou pelo uso do parasitóide $C$. flavipes (Cameron). Desde a sua primeira liberação em lavouras de cana-deaçúcar em Alagoas, em julho de 1974, observou-se vantagem no controle da broca. No estado de São Paulo o programa de controle biológico da broca com C. flavipes iniciou-se em 1977, sendo que em 1991 haviam liberado 943 milhões de adultos desse parasitóide e que a porcentagem de intensidade de infestação da praga, em canaviais de 26 usinas, tinha sido reduzida de uma média superior a 9\% em 1980 para 3,17\% em 1991 (CEBRASA, 2008).

Segundo Pinto (2006), o controle biológico é utilizado intensamente para controlar as pragas principais da cultura, ou seja, a broca-da-cana, principalmente no sudeste do país, e a cigarrinha-das-folhas, na região nordeste. No caso da broca-da-cana, utiliza-se o parasitóide larval $C$. flavipes, que é liberado em cerca de 1.700.000 ha, num programa de controle biológico difícil de ser superado em todo o mundo, pela sua eficiência e pela extensão coberta, em relação a outros países.

Como medida de controle cultural, o controle biológico com o parasitóide $C$. flavipes é uma alternativa não convencional de manejo dessa praga que contribuiu significativamente para a diminuição do impacto da broca sobre a cana. Isto significou uma economia de 88,4 milhões, pois deixaram de ser aplicados mais de 700.000 litros de inseticidas para o controle da broca-da-cana. O uso dos agentes de controle biológico corresponde cerca de $1 \%$ do mercado mundial de inseticidas (POLANCZYK et al., 2004).

Afirmam Cirelli e Penteado Dias (2003), que a utilização de inseticidas químicos para o controle da broca-da-cana não é recomendada devido aos prejuízos ambientais provocados e pela forma de aplicação dos mesmos na lavoura, que torna difícil a sua penetração no interior dos colmos onde as lagartas provocam os maiores prejuízos. Devido a essas restrições e a necessidade de alternativas seguras aos inseticidas químicos, tem-se aumentado o interesse por agentes biológicos para o controle da praga, sendo a vespinha $C$. flavipes o exemplo de programa de controle biológico bem sucedido no Brasil.

Observam Nakano et al. (2002), que o fator chave para evitar o crescimento populacional da broca é a eliminação dos seus ovos e das lagartas, por meio do uso de inimigos naturais, sendo a principal espécie predadora de ovos da broca-da-cana, o parasitóide Trichogramma galloi (Hymenoptera: Trichogrammatidae). Recomenda-se que a liberação desse parasitóide, seja feita na forma adulta, em 25 pontos/ha, num total de 200 mil parasitóides/ha em três liberações sucessivas, feitas à tarde e espaçadas de uma semana. Aconselha-se também que esse parasitóide deve ser associado ao parasitóide de lagartas Cotesia flavipes (Hymenoptera: Braconidae). 
Botelho (1992) realizou um trabalho no período de 1978 e 1989 na região de abrangência da COSUL - IAA/PLANALSUCAR comparando a eficiência de vários parasitóides de D. saccharalis: Metagonistylum minense Towns., Apanteles flavipes $(=C$. flavipes) Cameron, Paratheresia claripalpis Wulp. e outros. Foi constatado que A. flavipes surgiu como principal inimigo natural da broca, com uma participação de $76,64 \%$ no parasitismo total obtido no ano de 1989.

Outro trabalho envolvendo a porcentagem de parasitismo da C. flavipes (Cameron) e outros parasitóides (principalmente Metagonistylum minense Towns. e Paratheresia claripalpis Wulp.) foi desenvolvido por Macedo (2000) durante 22 anos (entre 1975 e 1997) nos canaviais da Usina da Barra, Barra Bonita, SP. Esse trabalho também abordou a Intensidade de Infestação (I. I. \%) pela D. saccharalis (Fabricius). Macedo (2000) obteve os seguintes resultados: a $C$. flavipes apresentou maior porcentagem de parasitismo e a Intensidade de Infestação pela broca da cana se tornou cada vez menor.

Quanto ao assunto, Parra (2000) acrescenta que os inimigos naturais da broca-da-cana são predadores, parasitóides e microrganismos. Todos esses inimigos podem ser utilizados e produzidos em laboratório levando em conta sua biologia, mas em termos de custo, manipulação e taxonomia (por serem mais conhecidos) os parasitóides são os mais utilizados.

Existem três tipos de criações de insetos em laboratório, em pequena escala, comercial e massal (PARRA, 1992).

Conforme Odum (1988), os parasitóides são organismos intermediários entre predadores e parasitas.

Segundo Odum (1988); Ricklefs (2003), os parasitóides possuem algumas características de parasitas porque têm um hospedeiro específico e alto potencial biótico, ou seja, capacidade natural de crescimento da população, residindo no interior de um hospedeiro vivo e comendo seus tecidos, que por conta disso fazem também o papel de predador, pois inevitavelmente matam seus hospedeiros.

Conforme o Instituto Biológico (2009) existem dois tipos de parasitóides, o endoparasitóide que ataca dentro do organismo do hospedeiro e o ectoparasitóide que propaga externamente ao corpo do hospedeiro.

Com a finalidade de controlar a broca-da-cana, Macedo (2000) orienta que para não ocorrer prejuízo ao meio ambiente, inimigos naturais são produzidos em laboratório. Apesar dessa praga possuir vários inimigos naturais, a vespa C. flavipes (Cameron) (Hymenoptera: Braconidae) é a mais utilizada. Em várias utilizações, esse parasitóide foi o mais eficiente na 
diminuição da população da D. saccharalis (Fabricius), quando comparado com outros parasitóides.

Outra forma eficiente de manejo da broca é a utilização de feromônio (NAKANO et al. 2002). Para isso, colocam-se em condições de campo, armadilhas contendo fêmeas virgens com até 48 horas de idade, no interior de pequenas gaiolas. Os machos atraídos são coletados dentro de uma bandeja com água e melaço ou detergente.

As perdas provocadas pela broca-da-cana podem chegar a 35,0 $\mathrm{kg}$ de açúcar/ha e a 30,0 litros de álcool/ha com apenas 1\% de colmos broqueados (BUG Agentes Biológicos, 2009). Em estudos realizados por Precetti et al. (1988), mostraram que para cada $1 \%$ de infestação, os índices médios de perda de açúcar foram de $0,370 \mathrm{~kg} / \mathrm{ton}$ de cana e de álcool e 0,165 1/ton cana.

Afirma Nardin (2002), que para uma produção de 1.250 .000 ton perde-se 9.650 ton ou 112 ha.

O aumento da produtividade brasileira de cana-de-açúcar deve muito ao desenvolvimento de variedades mais ricas em açúcar e ao programa de controle biológico da broca da cana-de-açúcar, $D$. saccharalis, que diminuiu a intensidade de infestação de 10 para 2\% em uma década (PINTO, 2006).

Segundo Papa (2007), a melhor estratégia de controle não é o método químico, varietal ou biológico, e sim um trabalho que integre harmonicamente estes métodos. Não é desejável de forma alguma que o controle químico venha a substituir o controle biológico aplicado e sim que venha a ser mais uma ferramenta disponível ao produtor. A cana-de-açúcar é uma cultura semi-perene com certas particularidades em relação ao controle da broca que devem ser levadas em consideração no momento de traçar as estratégias de controle. Em determinados panoramas, torna-se necessário o uso de alternativas de combate, como o emprego de inseticidas, que sejam compatíveis com o controle biológico. Por exemplo, existem variedades que são mais suscetíveis ao ataque da broca. Áreas que são destinadas à produção de mudas também devem receber cuidados especiais, devido a sua função de matriz.

No campo constata-se claramente em qualquer cultura plantada em extensas áreas, que o controle de pragas calcado em um método utilizado de forma isolada e única não se sustenta em longo prazo. No caso da cana-de-açúcar, a associação do controle biológico aplicado com o controle químico moderno que apregoa o uso de inseticidas de notável seletividade aos inimigos naturais e um baixo impacto ambiental poderá ser uma forma mais racional do manejo da broca, auxiliando de forma fundamental a expansão da cultura que já é uma realidade na agricultura brasileira (PAPA, 2007). 


\section{CONCLUSÃO}

Pelo trabalho concluiu-se que, os danos causados pela broca influenciam principalmente na produtividade e qualidade da cana-de-açúcar.

O controle biológico da Diatraea saccharalis pelo parasitóide Cotesia flavipes, é uma prática cada vez mais utilizada nas regiões onde se cultiva a cana-de-açúcar.

Além da eficiência comprovada da Cotesia flavipes em parasitar a praga e da dificuldade em controlar a broca com produtos químicos, este método possui ainda algumas vantagens, tais como: facilidade de criação em laboratório e liberação no campo, interrupção do ciclo evolutivo da praga, não provoca desequilíbrio à fauna benéfica, não deixa resíduos. Portanto, o controle biológico traz somente benefícios às usinas e ao meio ambiente.

\section{REFERÊNCIAS}

AGRIANUAL 2009: anuário da agricultura brasileiro. São Paulo: IFNP, 2009. 497p.

AGROBYTE. Cana-de-açúcar. 2009. Disponível em:<

http://www.agrobyte.com.br/cana.htm>. Acesso em: 05 jun. 2009.

ALTIERI, M. C.; SILVA, E. N.; NICHOLLS, C. I. O papel da biodiversidade no manejo de pragas. Ribeirão Preto: Holos, 2003. 226 p.

ALVES, S. B.; LOPES, R. B. Controle microbiano de pragas na América Latina: avanços e desafios. Piracicaba: Fealq, 2008, 414p. (Biblioteca de Ciências Agrárias Luiz de Queiroz, $14)$.

BELLOTTI, A. C. Controle biológico no contexto da agricultura sustentável. In: SIMPÓSIO DE CONTROLE BIOLÓGICO, 3.Anais... 1992, p. 3.

BOTELHO, P. S. M. Quinze anos de controle biológico da Diatraea saccharalis utilizando parasitóides. Pesquisa Agropecuária Brasileira, Brasília, v.27, p. 254, 261 e 262. abr. 1992.

BRAGA, B. et al. Introdução à engenharia ambiental. São Paulo: Prentice Hall, 2003, p.143.

BUG Agentes Biológicos. Disponível em:<http:www.bugagentesbiologicos.com.br $>$. Acesso em: 05 jun. 2009.

CANAOESTE. A cana-de-açúcar no Brasil. Disponível em:

<http://www.canaoeste.com.br/>. Acesso em: 05 jun. 2009. 
CARVALHO, E. P. de. Espaço para crescer. UNICA (União da Indústria da cana-deaçúcar). Disponível em:

http://www.portalunica.com.br/portalunica/index.php?Secao=referência\&SubSecao=opinião

$\&$ SubSubcecao=artigos\&id=\%20and\%20id=114>. Acesso em: 05 jun. 2009.

CEBRASA. Centro de Soluções Ambientais. Controle biológico. 2008. Disponível em:< http://www.cebrasa.agr.br/controle_biologico.html>. Acesso em: 05 jun. 2009.

CESNIK, R.; MIOCQUE, J. Melhoramento da cana-de-açúcar. Brasília: Embrapa Informação Tecnológica, 2004. 307p.

CIRELLI, K. R. N; PENTEADO-DIAS. A. M. Análise da riqueza da fauna de Braconidae (Hymenoptera: Ichneumonoidea) em remanescentes naturais da Área de Proteção Ambiental (APA) de Descalvado, SP. Revista Brasileira de Entomologia. v.47, n.1, p. 89-98, 2003.

COLBORN. T.; DUMANOSKI, D.; MYERS, J. P. O futuro roubado. Porto Alegre: Ed. L \& PM, 354p. 1997.

CTC. Centro de Tecnologia Canavieira. Tecnologia em cana-de-açúcar para a região Nordeste. Disponível em:<

http://www.ctcanavieira.com.br/index.php?id=61\&option=com_content\&task=view. Acesso em: 27 jul. 2009.

FUSER, I. Os perigos da monocultura. Revista Atualidades Vestibular, 2008, 241p.

GALLO, D. et al. Manual de entomologia agrícola. São Paulo: Agronômica Ceres, 1988, 649 p.

GALLO, D. et al. Entomologia agrícola. Piracicaba: FEALQ, 2002. 920p.

GUAGLIUMI, P. Pragas da cana-de-açúcar no nordeste do Brasil. Rio de Janeiro: Instituto do Açúcar e do Álcool. Col. Canav., 622p., 1972/73.

INSTITUTO BIOLÓGICO. Biologia reprodutiva de Cotesia flavipes (Cameron) (Hymenoptera: Braconidae) V. avaliação do número de posturas, prole e razão sexual do parasitóide em relação ao tamanho do hospedeiro Diatraea saccharalis Fabricius (Lepidóptera: Pyralidae). Disponível

em:<http://www.biologico.sp.gov.br/arquivos/v67_2/15.htm>. Acesso em: 05 jun. 2009.

KING, N. J.; MUNGOMERY, R. W.; HUGUES, C. G. Manual of cane growing. New York, Elsevier, 1965.

LANDELL, M. G. A.; CAMPANA, M. P.; FIGUEIREDO, P.; SILVA, M. A. Programa de melhoramento genético: estratégias para o desenvolvimento de novas variedades de cana-de-açúcar. In: LANDELL M. G. A.; VASCONCELOS, A. C. M.; DINARDO-

MIRANDA, L. L. (Coords.) WORKSHOP, 2, Programa Cana IAC. Instituto Agronômico de Campinas. p. 7-10. 2003a. 
LANDELL, M. G. A.; FIGUEIREDO, P.; VASCONCELOS, A. C. M.. O estado da arte da pesquisa em cana-de-açúcar na região Centro-sul do Brasil. In: REUNIÃO ITINERANTE DE FITOSSANIDADE DO INSTITUTO BIOLÓGICO - RIFIB, 9, 2003b, Catanduva, SP.

Anais... p.1-9. 2003b.

LUCHINI, L. C. Contaminação ambiental por agroquímicos. In: CICLO SOBRE

CONTROLE BIOLÓGICO DE PRAGAS. 4, 1999, Campinas, SP, Anais... p.24-27, 1999.

MACEDO, N.; BOTELHO, P. S. M. Controle integrado da broca cana-de-açúcar Diatraea saccharalis (Fabr. 1794) (Lepidoptera: Pyralidae). Brasil Açucareiro, v.106, p.2-12, 1988.

MACEDO, N. Método de criação do parasitóide Cotesia flavipes (Cameron, 1981). In: BUENO, V. H. P. (Ed.). Controle biológico de pragas: produção massal e controle de qualidade. Lavras: UFLA, 2000. cap. 9, p.161-166 e 172.

MACHADO, L. A. Criações de insetos de laboratório para utilização em pesquisas de controle biológico. In: CRUZ, B. P. B. (Coord.). Pragas das culturas e controle biológico. Campinas: Fundação Cargill, 1988, p.8.

MACHADO, L. A.; HABIB, M. Perspectivas e impactos da cultura de cana-de-açúcar no Brasil. 2009. Artigo em Hypertexto. Disponível em:

<http://www.infobibos.com/Artigos/2009_2/Cana/index.htm>. Acesso em: 27 jul. 2009.

NAKANO, O.; ROMANO, F. C. B.; PESSINI, M. M. O. Broca do rizoma (Migdolus spp.) In: NAKANO, O., ROMANO, F. C. B., PESSINI, M. M. O. (Eds.). Pragas de Solo. Piracicaba, SP: ESALQ/USP, p.25-35, 2001.

NAKANO et al. Entomologia agrícola. Piracicaba: FEALQ, 2002, 920p.

NARDIN, R. R. Treinamento do setor de entomologia de Grupo Virgolino de Oliveira açúcar e álcool. In: GRUPO VIRGOLINO DE OLIVEIRA, 2002, Itapira, p.2, 3 e 6.

ODUM, E. P. Ecologia. Rio de Janeiro: Guanabara Koogan, 1988, p.184, 185 e 244.

PAPA, G. Broca da cana-de-açúcar. 2007. UNESP/ Ilha Solteira. Disponível em:< http://www.ilhasolteira.com.br/colunas/index.php?acao=verartigo\&idartigo=1194012462>. Acesso em: 27 jul. 2009.

PARRA, J. R. P. Criação massal dos inimigos naturais. In: CRUZ, B. P. B.; FILHO, A. B.; LEITE, L. G. (Coord.). CICLO DE PALESTRAS SOBRE CONTROLE BIOLÓGICO DE PRAGAS. 2, Campinas, Fundação Cargill, mar. 1992, p.5 e 6.

PARRA, J. R. P. A biologia de insetos e o manejo de pragas: da criação em laboratório à aplicação em campo. O controle biológico e o manejo de pragas: passado, presente e futuro. In: GUEDES, J. C.; COSTA, I. D.; CASTIGLIONI, E. (Coord.). Bases e técnicas do manejo de insetos. Santa Maria: UFSM/CCR/DFS, 2000, cap.4, p.59-61, 63-68.

PINTO, A. de S. Controle de pragas da cana-de-açúcar. Sertãozinho: Biocontrol, 2006, 64p. (Boletim Técnico Biocontrol, n.1).

POLANCZYK, R. A. et al. Pragas de cana-de-açúcar $\mathbf{x}$ métodos alternativos de controle. Biotecnologia Ciência \& Desenvolvimento, Brasil, v. 33, p. 12-15, 2004. 
PRECETTI, A. C. M. et al. Perdas de produção em cana de açúcar, causadas pela saúva mata pasto, Atta bisphaerica. Parte I. Boletim Técnico COPERSUCAR 42/88 p. 25-30, 1988.

RICKLEFS, R. E. A economia da natureza. 5.ed. Rio de Janeiro: Guanabara Koogan, 2003, p.211-213, 305-306.

SANGUINO, A. Situação atual da pesquisa em doenças da cana-de-açúcar. Summa Phytopathologica. v.24, n.1, p.90-91, 1998.

SANTOS, A. S. Doenças causadas por fungos e bactérias em cana-de-açúcar. In: REUNIÃO ITINERANTE DE FITOSSANIDADE DO INSTITUTO BIOLÓGICO - RIFIB, 9, Catanduva, SP. Anais... p.10-17, 2003.

UNICA. União da Indústria de Cana-de-Açúcar. Unica: safra de cana 08/09 simbolizará 500 anos em cinco. Disponível em:

<http://www.udop.com.br/geral.php?item=noticia\&cod=89698>. Acesso em: 05 jun. 2009. 
